\title{
Effects of Land Cover Change on Urban Floods and Rainwater Harvesting: A Case Study in Sharjah, UAE
}

\author{
Abdallah Shanableh ${ }^{1,2}$, Rami Al-Ruzouq ${ }^{1,2, *(1)}$, Abdullah Gokhan Yilmaz ${ }^{1,2}$, \\ Mohsin Siddique ${ }^{1,2}$, Tarek Merabtene ${ }^{1,2}$ (i) and Monzur Alam Imteaz ${ }^{3}$ \\ 1 Research Institute of Sciences and Engineering, University of Sharjah, 27272 Sharjah, UAE; \\ shanableh@sharjah.ac.ae (A.S.); ayilmaz@sharjah.ac.ae (A.G.Y.); msiddique@sharjah.ac.ae (M.S.); \\ tmerabtene@sharjah.ac.ae (T.M.) \\ 2 Department of Civil and Environmental Engineering, University of Sharjah, 27272 Sharjah, UAE \\ 3 Civil Engineering Department, Swinburne University of Technology, 3122 Melbourne, Australia; \\ mimteaz@swin.edu.au \\ * Correspondence: ralruzouq@sharjah.ac.ae; Tel.: +971-6-505-0953
}

Received: 9 March 2018; Accepted: 10 May 2018; Published: 13 May 2018

\begin{abstract}
In this study, multi-temporal satellite images combined with rainfall data and field observations were used to assess the spatial and temporal changes in urban flooding and urban water harvesting potential in the coastal city of Sharjah, United Arab Emirates (UAE) during the period from 1976 to 2016. During the study period, the population increased by approximately 14-fold with about a 4-fold increase in built areas. Being in a hot, dry region with average rainfall of about $100 \mathrm{~mm}$ /year, the city did not invest in a comprehensive drainage infrastructure. As a result, the frequency, extent and risk associated with urban floods increased significantly. The expansion of built areas progressively increased the impervious land cover in the city, decreasing the minimum precipitation required to generate runoff by approximately $32 \%$ and significantly increasing the runoff coefficient. In parallel to rapid urbanization, the urban rainwater harvesting potential significantly increased over 1976-2016. Urban flood maps were generated using three thematic factors: excess rain, land elevation and land slope. The flood maps were confirmed by locating urban flood locations in the field using GPS. This study demonstrates the impact of urbanization through assessing the relationship between urbanization, runoff, local floods and rainwater harvesting potential in Sharjah and provides a basis for developing sustainable urban storm water management practices for the city and similar cities.
\end{abstract}

Keywords: urbanization; multi-temporal satellite images; urban rainwater harvesting; flood mapping; storm water management

\section{Introduction}

Population growth and the shift of people from rural to urban areas is increasing the demand for the expansion of urban areas. Rapid urbanization brings several environmental problems, such as the urban heat island effect, changes in hydrological processes and water resources, contribution to climate change and the extinction of species [1]. Urbanization causes alterations in hydrological processes through change in surface infiltration characteristics due to an increasing impervious surface area. An increased built area results in a decrease in infiltration, baseflow and lag times, and an increase in runoff volumes, peak discharge and frequency of floods [2-4].

Sharjah city is the capital of the Emirates of Sharjah, one of seven emirates (i.e., states) that make up the United Arab Emirates. Sharjah generally experiences short-term precipitation, occasionally with high intensity causing flash floods, which are compounded due to urbanization. Sharjah has grown 
rapidly over the last 50 years as evidenced by population growth and expansion of built areas. This rapid urbanization changed the land cover and significantly modified the hydrological characteristics of the area (e.g., runoff, infiltration). With increased urbanization, the frequency and severity of local floods in Sharjah have increased substantially. The increased intensity and frequency of floods in Sharjah has prompted city authorities to consider investing in a proper drainage system for the city. The main challenge is to justify a massive investment in rainwater management infrastructure to handle infrequent rainfall events. Therefore, there is a significant need to investigate the effects of urbanization and other factors (such as climate change) on floods in Sharjah city.

Several researchers have investigated the influence of urbanization on the hydrological response of watersheds. For example, Choi, Engel, Muthukrishnan and Harbor [5] adopted the Cell Based Long Term Hydrological model (CELTHYM) to investigate the effects of land cover change (urbanization) on hydrology of a basin in central Indiana. Franczyk and Chang [6] investigated the effects of climate change and urbanization on runoff in the Rock Creek Basin in the Portland Metropolitan area. Chu, Lin, Huang, Hsu and Chen [7] used the distributed hydrological model to examine the relationship between land cover change and [8] hydrology of the Wu-Tu watershed in Northern Taiwan. Zope, Eldho and Jothiprakash [9] found marginal increases in the runoff peak discharges and volumes within the catchment as a result of land use-land cover change in the Mithi River catchment in Mumbai, India. Nigussie and Altunkaynak [10] examined the effects of urbanization on the hydrological response of the Ayamama watershed in Istanbul, Turkey using the SLEUTH urban growth model and the HEC-1 hydrological model. Al-Rawas et al. [11] investigated the effects of urban form on curve number use in rainfall runoff modelling in Oman. In their study, standard CN values were modified in the residential land use zone to achieve more precise rainfall runoff modelling. Sharif et al. [8] examined the effects of urbanization on flood hazards in Riyadh, Saudi Arabia using GIS and remote sensing-based data in hydrologic models, and flood hazard zones were identified in this study. Huang et al. [12] studied the influence of urbanization on urban pluvial flooding in Shanghai, China. In this paper, land use/cover change effects on floods were investigated for the years 2000, 2006 and 2012 using a range of rainfall events. Readers are also directed to refs. [13-16] for examples of studies investigating the relationship between land use change and hydrological responses of the catchments.

Although urbanization effects on changes in runoff (therefore, floods) have been studied extensively around the world $[3,17,18]$, there is a significant need to study the flood and urbanization relationship in Sharjah city. To the knowledge of the current authors, there are no comprehensive studies in the literature investigating the urbanization effects on floods for Sharjah city. Although Shanableh and Al-Ruzouq [19] and Shanableh et al. [20] investigated land cover change and urbanization in Sharjah city, neither of these studies focused on the urbanization and flood relationship. In the current study, first, the temporal and spatial variation of land cover change and associated impacts on runoff were assessed using satellite images coupled with a geographic information system (GIS) over the period from 1976-2016. Then, local flood maps for Sharjah city were created in a GIS environment considering three factors: excess rain, elevation, and the slope. Finally, the rainwater harvesting capacity of Sharjah city, as a component of sustainable flood management, was investigated. This study is expected to make a significant contribution to the study area as one of the earliest studies on the relationship between urbanization, runoff, local floods and the rainwater harvesting capacity in Sharjah.

\section{Study Area}

The Sharjah city has geographical coordinates of $25.3^{\circ} \mathrm{N} 55.5^{\circ} \mathrm{E}$ and is located on the coast of the Arabian Gulf. It is in a hot, dry region, with daily temperature highs of $24-42{ }^{\circ} \mathrm{C}$ and mean temperatures of $18-34{ }^{\circ} \mathrm{C}$. The rainy season of Sharjah city typically occurs from December to March, and the average rainfall is about $100 \mathrm{~mm}$ /year. Figure 1 shows the UAE map and Landsat image of Sharjah city, with the study area identified. 

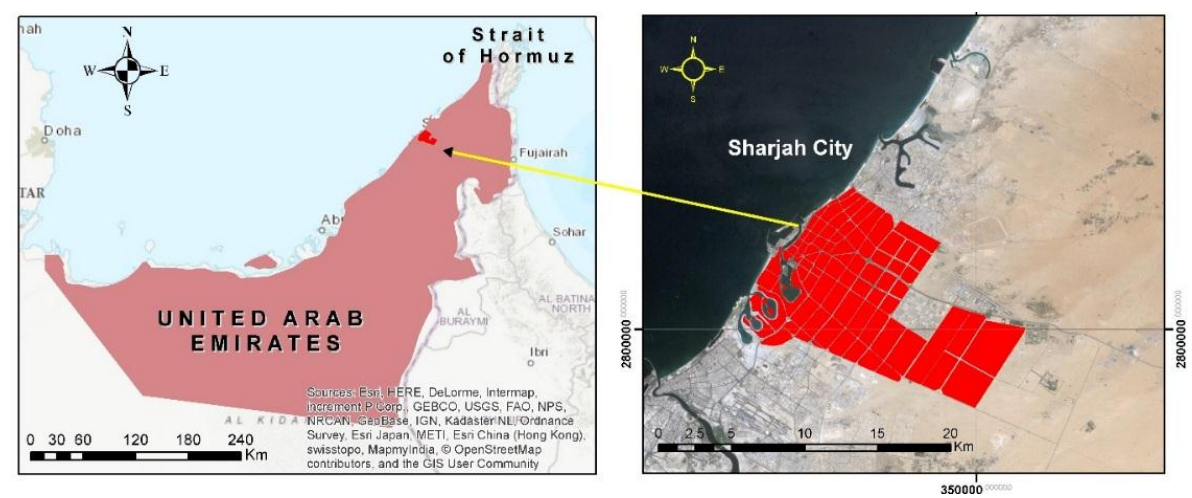

Figure 1. Location of Sharjah City in the United Arab Emirates.

\section{Methodology}

\subsection{Analysis of Land Cover Changes}

In this study, two methods were used to assess land cover changes in Sharjah city for the study period of 1976-2016: multi-temporal image analysis and manual digitization of land features [21,22]. In the first method, land cover changes were assessed through the detection and registration of linear features in multi-temporal Landsat satellite images obtained for the period from 1976-2016. The image analysis involved linear feature extraction, image registration and pixel subtraction using Landsat images with different spatial and temporal resolutions. Linear features (straight-line segments) have high semantics and can be reliably extracted from the images. These linear features (streets and buildings in urban areas) were used as the base for change detection. Selected well distributed points, which were the main intersections and corners of buildings, were manually digitized in these images to perform the registration process, where 10-15 points were used to drive the transformation parameters needed for the image registration. It should be noted that the accurate registration of multi-temporal imagery is considered as one of the most important component for reliable change detection [23].

The second method was based on classifying the different land cover features and digitizing them manually based on visual inspection and knowledge of the area. Older images typically had a lower resolution than recent images; however, many of the old features remained standing and appeared in recent images. As the digitization process is tedious, saturated urban blocks were digitized as units and the digitized areas were distributed between the different land use types by ratio. Figure 2 shows the land use classes in Sharjah city.

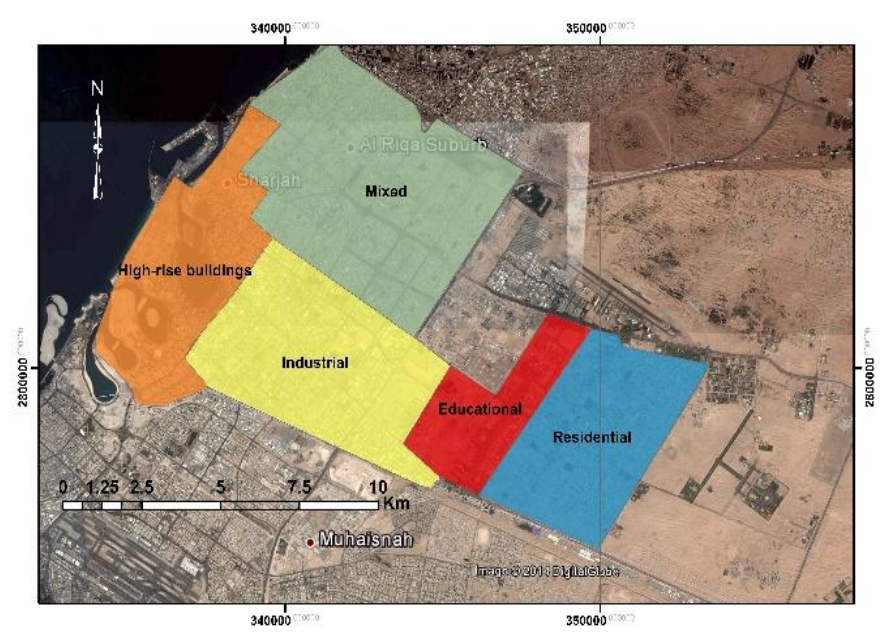

Figure 2. Land use classes within the study area. 


\subsection{Runoff Analysis}

The adopted approach to estimate the runoff in the city was based on the procedure outlined by Weng [24] in which the US Soil Conservation Service (SCS) model was used to provide a relative estimate of runoff changes due to land cover changes. The SCS method is based on assigning curve numbers $(\mathrm{CN})$ representing the runoff characteristics of the different land covers. The relevant SCS method equations are presented below:

$$
\begin{gathered}
\mathrm{Q}=\frac{(P-0.2 \times S)^{2}}{P+0.8 \times S}, \\
\mathrm{~S}=25.4 \times\left[\frac{1000}{\mathrm{CN}}-10\right],
\end{gathered}
$$

where, $S$ is the potential maximum storage, or $S_{P M a x}(\mathrm{~mm}), Q$ is the runoff depth $(\mathrm{mm}), P$ is the cumulative precipitation $(\mathrm{mm})$ and $\mathrm{CN}$ is the curve number.

Solving Equation (1) requires two parameters: $P$ and $C N$. Equation (1) suggests that the minimum amount of rain required to generate runoff is $0.2 \times S$. For a given antecedent moisture condition, the curve number is determined according to the type of urban land cover and the extent of urbanization. For the purpose of estimating appropriate $\mathrm{CN}$ values, the manually digitized features were divided into five land use zones: high-rise buildings, residential/commercial mixed-use, residential, industrial and educational. Each of the five zones was further subdivided into seven land cover classes: buildings, roads, paved parking/space, undisturbed soil, compacted soil, vegetation, and others. The undisturbed soil, compacted soil and vegetation were considered to be the undeveloped open area, whereas the remaining land features were considered to be built areas. Curve numbers, as shown in Table 1, were assigned to the different types of land cover based on standard SCS tables (USDA, Chapter 10, [25]). It should be noted that the majority of the soil in the study area fell into hydrologic soil group C (according to the USDA hydrologic soil group classification) with a loamy-sandy soil, and a non-uniform slope throughout.

Table 1. Curve numbers assigned to the different types of land cover.

\begin{tabular}{ccccccc}
\hline Built Area & Compact Soil & Undisturbed Soil & Vegetation & Roads & Paved Areas & Others \\
\hline 90 & 80 & 75 & 70 & 90 & 87 & 87 \\
\hline
\end{tabular}

An equivalent runoff coefficient, $C$, for each land cover feature was then estimated from runoff, $Q$, per precipitation event, $P$, as in Equation (3):

$$
C=\frac{Q}{P}
$$

In this study, runoff coefficients were calculated for each land cover feature (i.e., buildings, roads, paved area, undisturbed soil, compacted soil, vegetation and others) from 1976 to 2016, using Equation (3), for range of rainfall events. Then, the weighted mean runoff coefficient $\left(C_{\text {mean }}\right)$ was calculated for the entire study area from 1976-2016 using Equation (4):

$$
C_{\text {mean }}=\frac{\sum A_{i} \times c_{i}}{A_{T}}
$$

In Equation (4), $A_{i}$ represents the land cover area for each land cover feature, $C_{i}$ is the runoff coefficient for each land cover feature, and $A_{T}$ is the total area. Mathematically, Equation (4) expresses a linear relationship between $C_{\text {mean }}$ and the built area fraction because $A_{T}$ is constant and the $C_{i}$ values for the different land cover features do not change with an increase in the built fraction. 


\subsection{Rainfall Analysis}

The annual and average monthly rainfall in Sharjah during 1977-2014 is shown in Figure 3, based on rainfall data obtained from Sharjah Airport Authority. The statistical average, maximum, and minimum values of rainfall in Sharjah during the same period were $108.8 \mathrm{~mm}, 318.9 \mathrm{~mm}$ and $8.6 \mathrm{~mm}$, respectively. The rainy season in Sharjah may be considered to span over a period of six months (November to April), and the winter season extends over four months (December to March). An analysis of monthly rainfall showed that $93 \%$ of total annual rainfall occurred during the rainy season and $81 \%$ occurred during winter. The average annual rainfall $\left(R_{a}\right)$ data (shown with the trend line in Figure 3), indicates a statistically non-significant decreasing trend, as discussed in Merabtene et al. [26], and this trend can be represented by Equation (5) for the period 1977-2014:

$$
R_{a}=-0.9403 \times(\text { Year }-1977)+127.17
$$
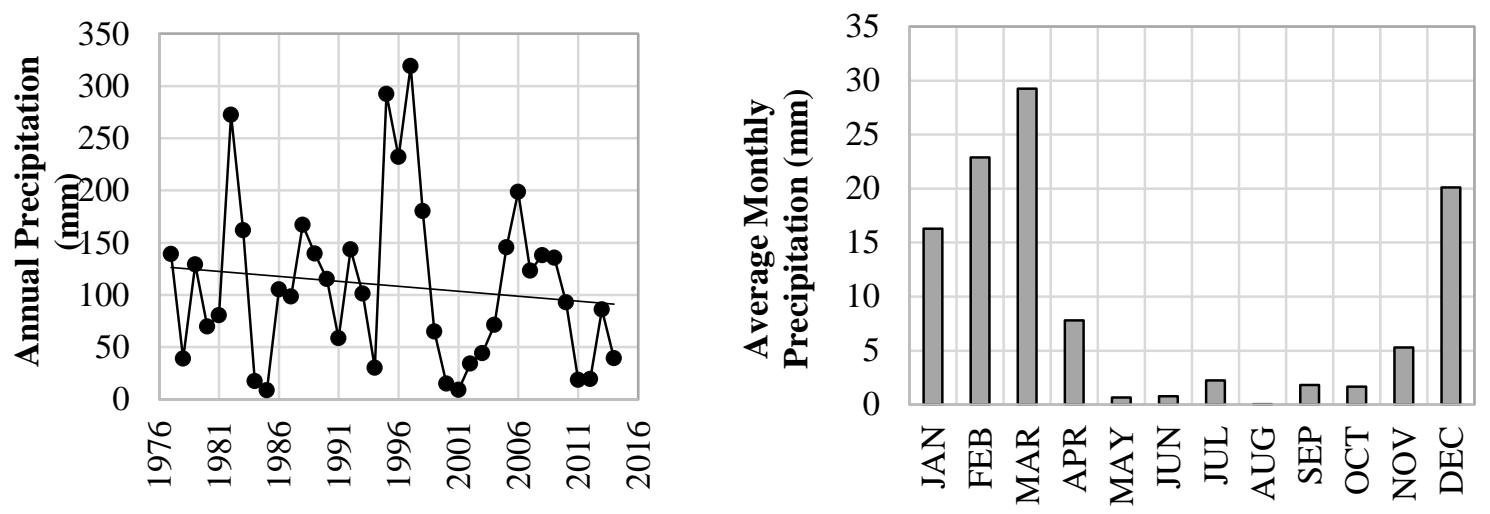

Figure 3. Annual and average monthly rainfall recorded at Sharjah International Airport during 1977-2014 and average annual rainfall during the same period (produced from Merabtene et al. [26]).

A range of intensity-duration-frequency (IDF) data based on IDF curves produced by Sherif et al. [27] are presented in Table 2. Table 2 shows that the range of precipitation per event is practically less than $100 \mathrm{~mm}$. In this study, the runoff characteristics were evaluated for precipitation events of less than $120 \mathrm{~mm}$.

Table 2. Range of rainfall intensity-duration-frequency and rainfall for the UAE desert foreland (Based on Sherif et al. [27]).

\begin{tabular}{ccccc}
\hline \multirow{2}{*}{ Duration (min) } & \multicolumn{2}{c}{$\mathbf{1 0 0 0}$ Year Return Period } & \multicolumn{2}{c}{ 2 Year Return Period } \\
\cline { 2 - 5 } & Intensity (mm/h) & Rainfall $\mathbf{( m m )}$ & Intensity $\mathbf{( m m} / \mathbf{h})$ & Rainfall $(\mathbf{m m})$ \\
\hline 5 & 250 & 21 & 50 & 4 \\
25 & 130 & 54 & 25 & 10 \\
50 & 75 & 63 & 18 & 15 \\
100 & 50 & 83 & 10 & 17 \\
150 & 35 & 88 & 7 & 18 \\
200 & 30 & 100 & 6 & 20 \\
\hline
\end{tabular}

Potential water harvesting was quantified based on an assumed recovery of $80 \%$ of precipitation from $80 \%$ of digitized buildings. The potential water harvest per capita was estimated using the estimated population of the city, as shown in Equation (6):

$$
\text { Harv. }=\frac{0.64 \times P \times A_{\text {Buildings }}}{\text { Population } \times \text { No. of Days }}
$$


Here $P$ represents the total precipitation and $A_{\text {Buildings }}$ is the total area of buildings. The number of days refers to the averaging period (annual 365 days, rainy season 180 days, winter 120 days).

\subsection{Generation of Local Flood Maps in Sharjah City}

The risk of local flooding depends on a number of factors, mainly precipitation, land cover, land slope, the presence of local depressions and obstructions, and the effectiveness of drainage facilities. In this study, localized flooding of Sharjah city was investigated, and flood maps of Sharjah were generated considering three thematic factors: excess rain (surface runoff), elevation and slope. These thematic factors were integrated with consideration of the weighted contribution of each factor into the flooding. To overcome the challenge of different measurement units and influencing factors, reclassification was implemented to unify all of the factors. In the reclassification process, each thematic factor was reclassified into five classes from one to five, where five represented the most effective class for flood occurrence and one was the least. For example, the "fifth" class of the "slope" factor was given to the least slope degree group, since, at low slopes, excess rain is accumulated and does not discharge; therefore, the chances for flood occurrence is higher at low slopes. It is important to note that "slope" and "elevation" contribute inversely to local flood occurrence, while "excess water" contributes directly to flood occurrence.

Each thematic factor has a different importance in terms of flood occurrence; therefore, each factor was weighted using the Analytical Hierarchy Process (AHP). The AHP is a multi-criteria decision analysis method that is adopted to decide the relative weights of available alternatives. Based on determined weights, the AHP can effectively prioritize choices among alternatives. The AHP an analytical tool that enables researchers to assign weights to tangible and intangible criteria against each other. This method has been widely used in flood analysis and it is based on three principles: decomposition, comparative judgment, and synthetization of priorities [28]. Generally, AHP has the ability to be used subjectively while minimizing inconsistency in judgment which is considered to be one of its advantages among other available methodologies. The AHP was used in this study since it is theoretically sound, readily understandable and simply implemented. The difficulty of the AHP method usually appears in the estimation of the input data and their preferences. However, different studies have been performed in different countries for flood risk assessment and flood plain management using AHP methodology [29-33].

In this study, the AHP was utilized to weight each thematic factor separately based on its importance. The weighting was accomplished based on a literature review and an expertise survey. The weights for the three factors were as follows: $60 \%$ for the excess water, $20 \%$ for the elevation, and $20 \%$ for the slope. To validate the generated flood maps, 99 points related to in-site flooding measurements were collected during the rainy seasons using Trimble Geo7@ Handheld GPS and the generated flood maps and collected flood data were compared.

\section{Results and Discussion}

\subsection{Land Cover Change and Urbanization of Sharjah City}

Example satellite images showing detected edges and digitized land cover features are shown in Figure 4. Sharjah city is surrounded by Dubai city to the south and Ajman city and the Gulf to the north. The old city was established close to the coastline on the Gulf (Figure 1). As the city grew and space along the coast between its Northern and Southern boundaries was filled, the city expanded inland away from the coast.

In this study, two approaches were adopted to quantify and assess the pattern of urbanization. The first approach relied on extracting linear features (buildings and roads) from multi-temporal satellite images [23,34-36], and the second approach relied on extracting linear features from vector (digitized) data [22]. The images in Figure 4 provide a visual estimation of expansion of built areas in the city for the years 1987 and 2014 as shown in the Landsat images, Figure 4a,b. As can be seen 
from Figure 4c (edge detection) and Figure 4d (manual digitization), there was a significant amount of urbanization (built up area expansion) over the years in the study area. The manually digitized images (Figure $4 b$ ) show that features in some areas were not digitized individually but rather, they were analyzed in blocks. This was due to the fact that the area had large warehouses with little separation between them. The digitization of blocks was also used in mixed use and other areas where building densities were high to simplify the tedious digitization process.

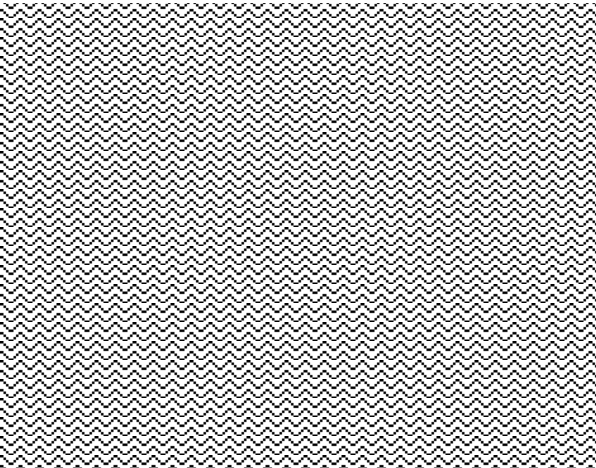

(a)

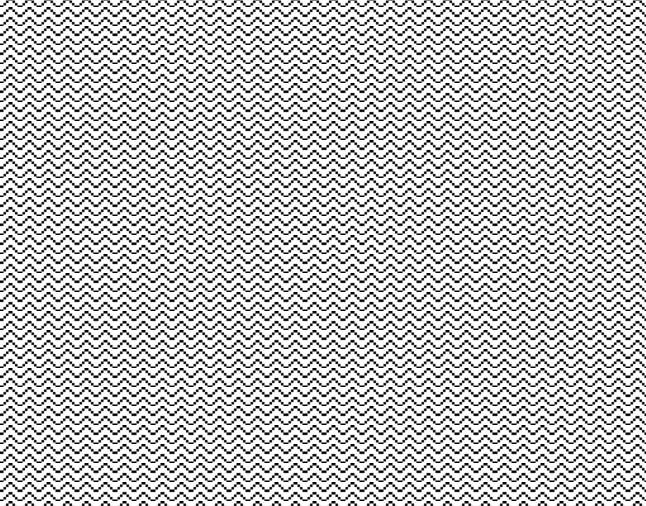

(c)

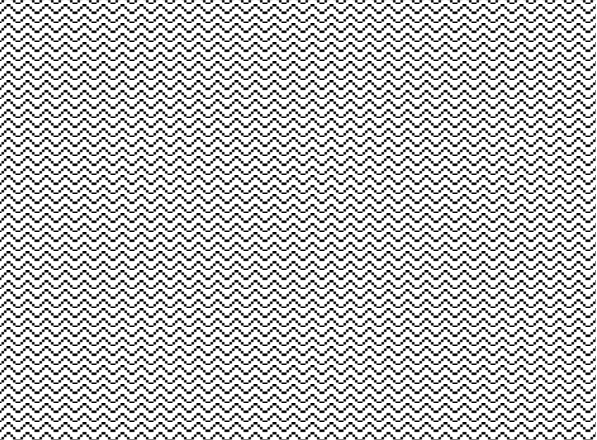

(b)

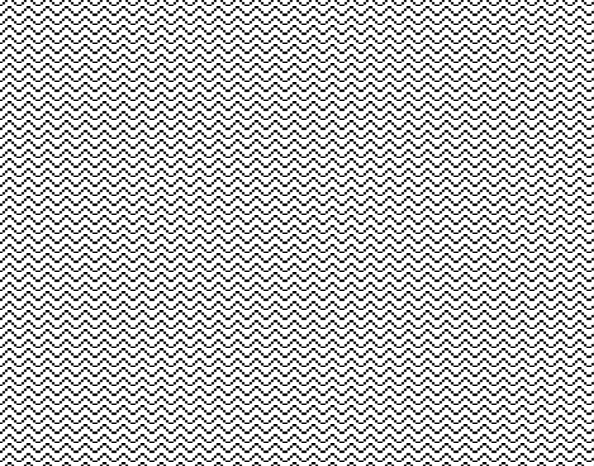

(d)

Figure 4. Estimation of land features using two methods: (a) Landsat image, 1987; (b) Landsat image, 2014; (c) edge detection of built features, 1987; and (d) direct digitization of features, 2014.

The seven land cover classes (buildings, roads, paved area, undisturbed soil, disturbed soil, vegetation, and others) in each of the five land uses changed during the study period as shown in Figure 5. Clearly, land covered by buildings, roads, paving materials, and vegetation expanded due to undisturbed and disturbed soil cover during the study period of 1976-2016.
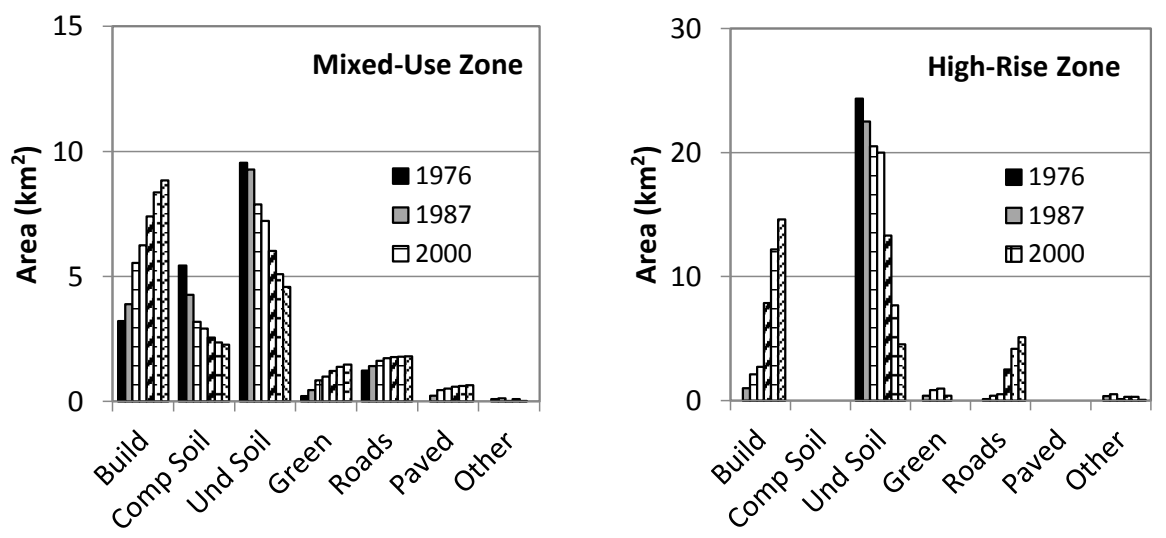

Figure 5. Cont. 

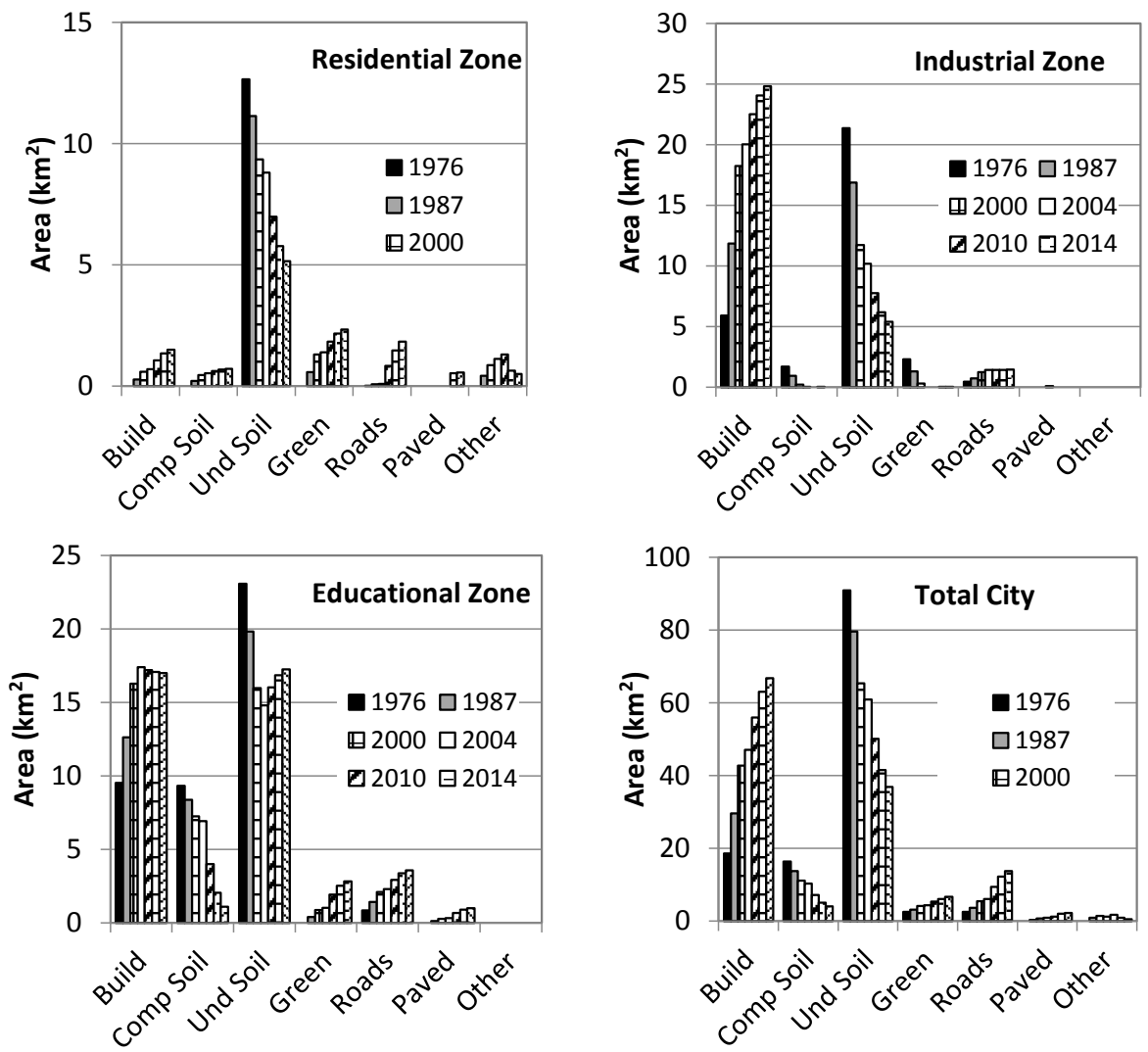

Figure 5. Land cover changes in the different land use zones of Sharjah City between 1976 and 2016.

The built area in each of the land use zones included buildings, roads, paved areas and other built land cover features. The undeveloped open area included undisturbed soil, disturbed soil and vegetation. Figure 6 shows the expansion of built areas in the various land use zones of the city during the period from 1976 to 2016 (years 1976, 1987, 2000, 2010, 2014 and 2016 are shown in the figure). Overall, the built areas expanded by approximately four times; from approximately $20 \mathrm{~km}^{2}$ (around $15 \%$ ) to about $80 \mathrm{~km}^{2}$ (around $60 \%$ ) out of approximately $130 \mathrm{~km}^{2}$ of total study area. At the same time, the undeveloped open areas declined from approximately $110 \mathrm{~km}^{2}(85 \%)$ in 1976 to about $50 \mathrm{~km}^{2}$ $(40 \%)$ in 2016. Figure 6 also shows the population growth in Sharjah city as being the most influential factor for expansion of the built area. The estimated population of Sharjah city (Figure 6) grew from approximately 80,000 people in 1976 to approximately 1 million in 2016, which represents a more than 10 -fold increase compared to the four-fold increase in built areas. The expansion of built areas and dramatic population growth reflect the rapid economic growth of Sharjah and the UAE during the study period.

The overall expansion of built areas and shrinkage of open areas in the city is shown in Figure 7. The built and open areas estimated from Landsat images using direct digitization (Figure 7a), and edge-detection (Figure $7 \mathrm{~b}$ ) techniques are shown in Figure 7. Compared to direct digitization, the edge-detection method significantly overestimated built areas and underestimated open areas. The areas estimated using the manual digitization technique were considered more representative of land features and were used in this study. 

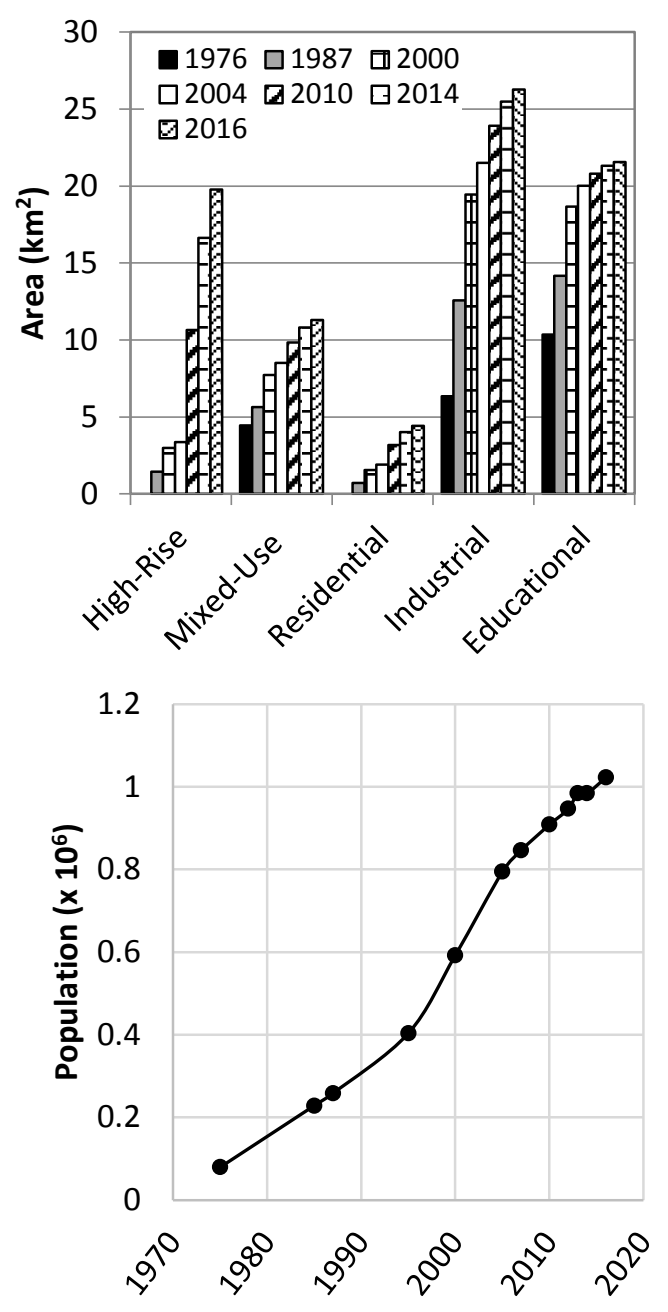

Figure 6. Expansion of built areas within the various land use zones and population growth in the city of Sharjah during 1976-2016.
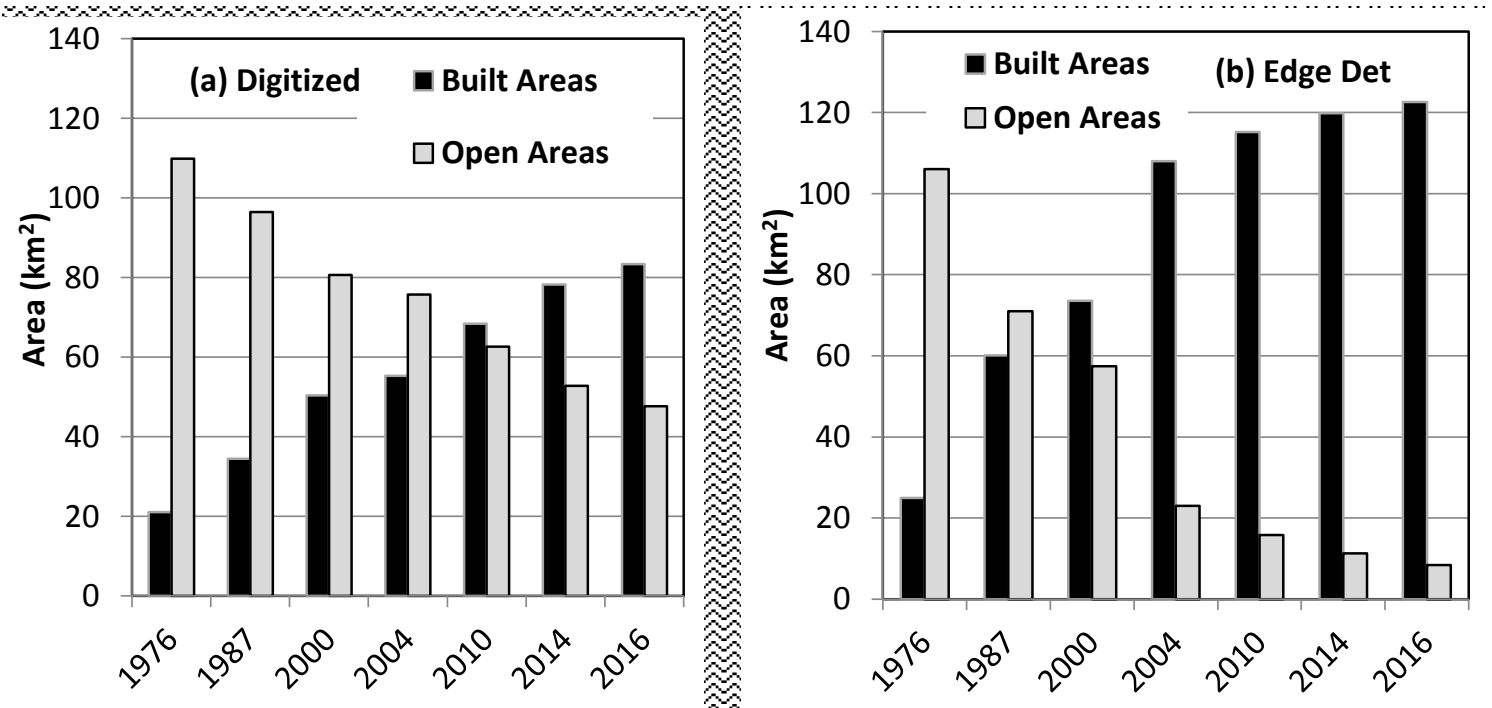

Figure 7. Comparison of built and open areas estimated from satellite images using two methods: (a) direct digitization of features; and (b) edge-detection. 


\subsection{Flooding Potential}

The historical expansion of built areas in the city (as discussed in Section 4.1) resulted in at least three impacts that increased the flood potential in Sharjah. These impacts were (1) an increase in the imperviousness of the land cover; (2) a reduction in the quantity of precipitation required to generate runoff; and (3) a reduction in the potential maximum storage. As a result, the potential flood severity and extent (as explained above) increased significantly in the city.

Examples of changes in flood characteristics during the period from 1976 to 2016 are shown graphically in Figure 8 . The minimum precipitation required to generate runoff $\left(P_{\text {Min }}\right)$ declined in the city as the built area increased over time, or as the impervious areas expanded. The minimum precipitation required to generate runoff in built areas declined from about $15 \mathrm{~mm}$ in 1976 to about $10 \mathrm{~mm}$ in 2016. Similarly, the potential maximum storage, $S_{P M a x}$, declined in the city over time as urbanization expanded from about $75 \mathrm{~mm}$ in 1976 to about $50 \mathrm{~mm}$ in 2016. Figure 8 shows linear decreasing trends for both $P_{M i n}$ and $S_{P M a x}$ with an increasing built fraction. An example showing excess rain (i.e., potential runoff at $40 \mathrm{~mm}$ precipitation) from the different categories of land cover over the study period is also shown. The data show that excess rain increased with time in the expanding built areas and decreased in the shrinking open areas. With the fraction of built areas (land cover with higher runoff coefficients) increasing from $15 \%$ in 1976 to approximately $60 \%$ in 2016, the runoff coefficient increased linearly (with built areas fraction), as seen in the example presented in Figure 8 at three different precipitation values. The data show that the runoff coefficient increased linearly with increasing urbanization in the city at the presented precipitation values.
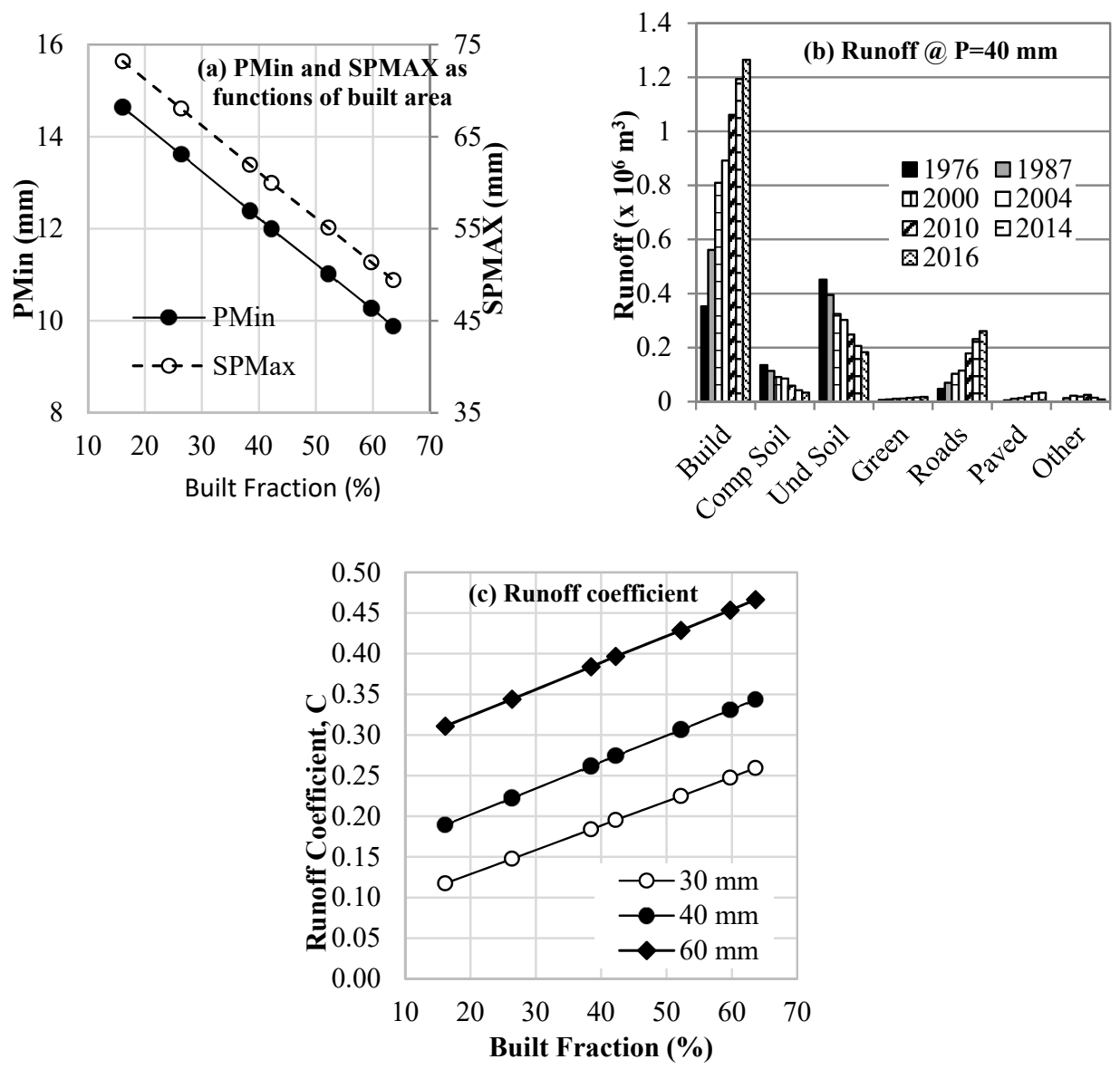

Figure 8. Impacts of the expansion of built areas during 1976 to 2016 on the minimum rain required to generate runoff $\left(P_{M i n}\right)$, the potential maximum land storage, $S_{P \max }$, the runoff at $40 \mathrm{~mm}$ precipitation, and the runoff coefficient. 


\subsection{Flood Maps in Sharjah City}

As explained in Section 3.4, local flood maps were generated using three thematic factors-excess rain, elevation and slope - and the accuracy of flood maps were checked with collected flood data through GPS. Figure 9 illustrates a flood map for Sharjah City generated by integrating the three factors along with field-collected flood coordinate positions, shown as dots or circles. The flooding map shows that most of the city is susceptible to flooding, which is consistent with field observations as the city is generally a flat, coastal area. The flood locations collected following a storm mostly corresponded to flooding locations predicted in the flood map. In fact, 89 out of 99 field-identified urban flood points matched flood points predicted in the flood map. In other words, the flooding map exhibited an accuracy of $89 \%$ in terms of prediction of flooding locations. Figure 10a shows flood maps for the years 2004 and 2014 and demonstrates how the urban flooding potential expanded with urbanization over a 10-year period. In fact, the frequency, extent and risk associated with urban floods increased significantly due to the expansion of built areas, which progressively increased the impervious land cover in the city.

As seen in Figure 10b, land cover in the residential land use zone significantly changed, from undisturbed soil to buildings. In parallel to rapid urbanization in residential land use zone, the flooding potential increased substantially in the residential land use zone. This can be seen as an evidence of a strong relationship between urbanization and floods. It can also be seen from Figure 10b that the industrial land use zone is very flood sensitive region. Figure 11a shows how the flooded area percentage changed from 2004 to 2014 for different land use zones. Figure $11 \mathrm{~b}$ illustrates the change in the built-up area (as an indicator of urbanization) between years 2004 and 2014 for different land use zones.

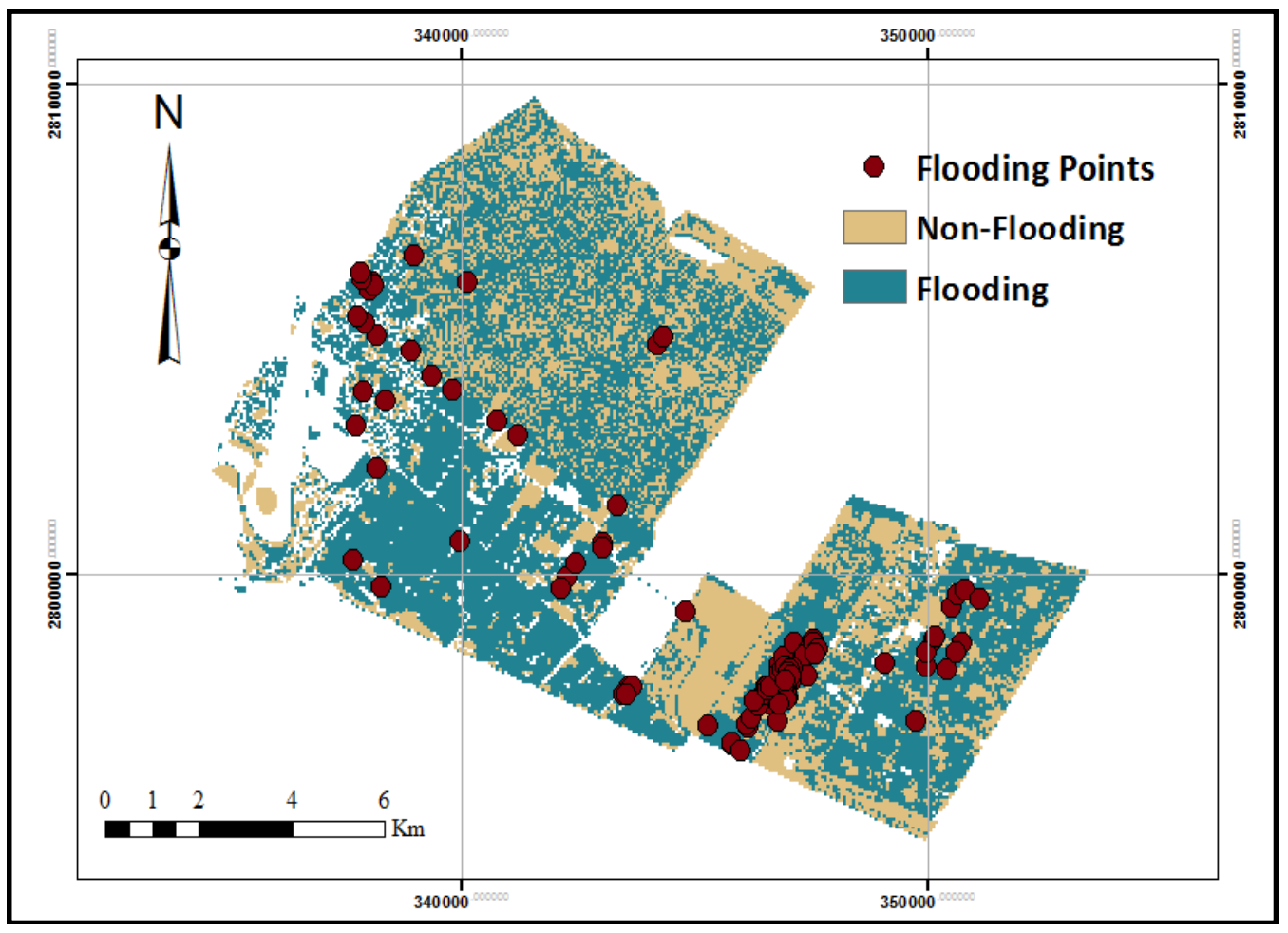

Figure 9. Flood map in Sharjah city along with field-collected flood positions. 

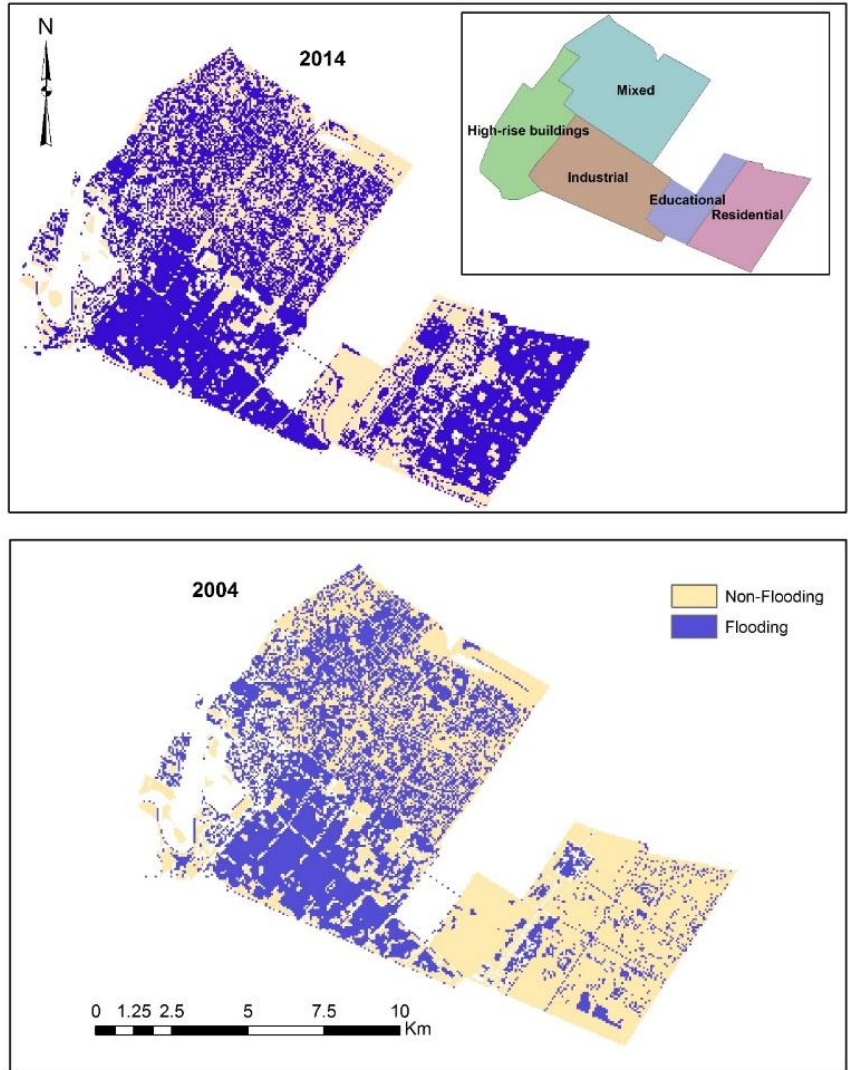

(a)
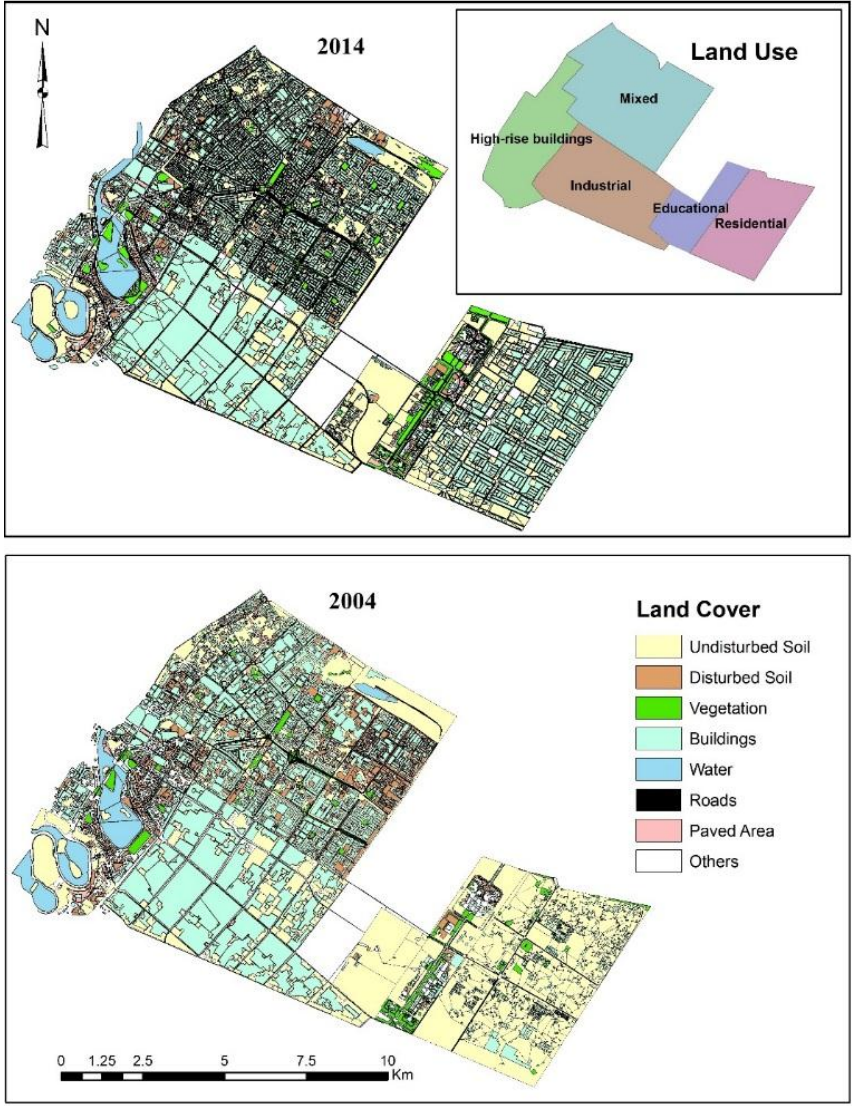

(b)

Figure 10. Flood and urbanization maps for years 2004 and 2014. (a) Flooding maps in 2004 and 2014; (b) land cover land use maps in 2004 and 2014. 

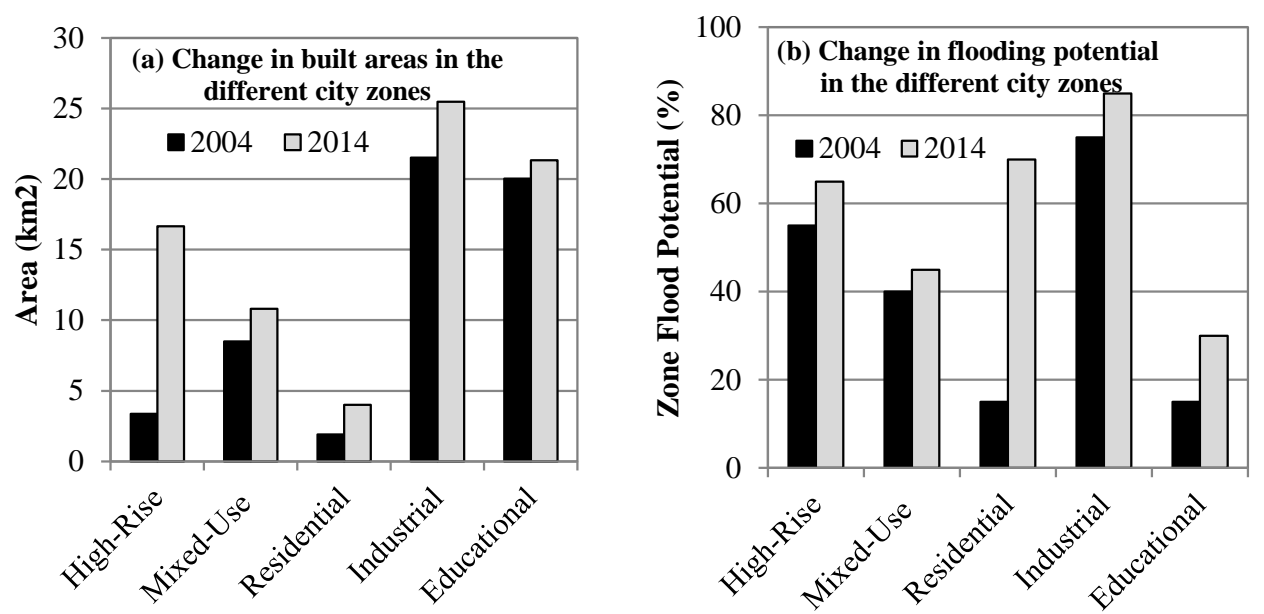

Figure 11. Change in areas prone to local urban flooding between 2004 and 2014 as a result of expansion of built areas in the different land use zones in Sharjah.

According to Figure 11, the largest increase in flooding percentage (i.e., percentage of flooded surface area to total surface area in the zone) was detected for the residential land use zone. The flooding percentage increased from around 10\% in 2004 to around 70\% in 2014 in the residential land use zone due to rapid urbanization. The second highest flooding percentage increase was detected in the education land use zone. Although the industrial land use zone is also sensitive to floods (as seen in Figures 9 and 10), there was not much change in the flooding percentage from 2004 to 2014, since urbanization in industrial land use zone did not show a large increase between 2004 and 2014, as can be seen in Figure 11. It can also be seen from Figure 12 that the residential land use zone showed the largest increase in flooding potential in Sharjah city followed by the educational and industrial land use zones, respectively.

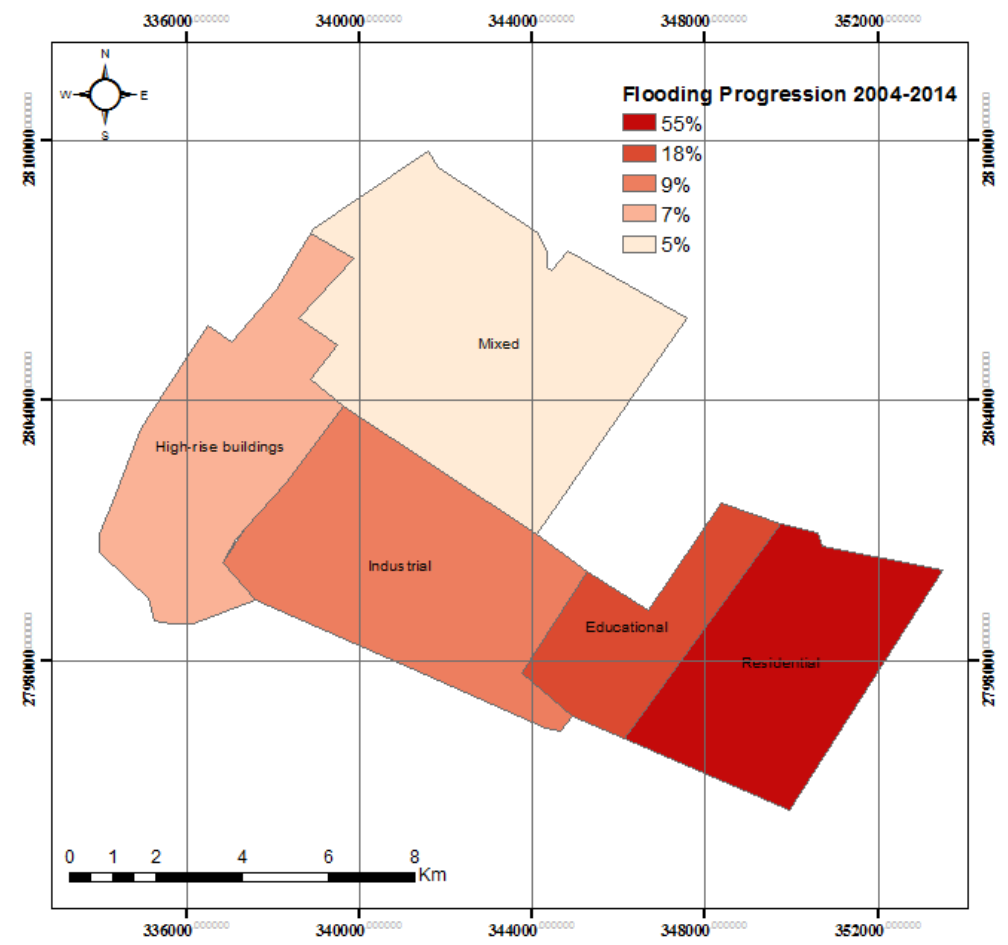

Figure 12. Flooding progression from 2004 to 2014. 


\subsection{Urban Rain Water Harvesting Potential}

The results presented in Figure 13 show the rainwater harvesting potential (in $\mathrm{m}^{3}$ ) from the rooftops of buildings, as well as the per capita potential for rainwater harvesting in the city, averaged over the whole year, over six months (rainy season), and over four months (winter season). In the calculations, the collectable fraction of rain was assumed to be $80 \%$ of precipitation. Figure 13 a shows that the potential water harvest in $\mathrm{m}^{3}$ increased over the years because of an increased area of rooftops. The data trends show that the increase in potential water harvest in $\mathrm{m}^{3}$ accelerated, starting from the year 2006, which is consistent with the boom in building activity starting that year.
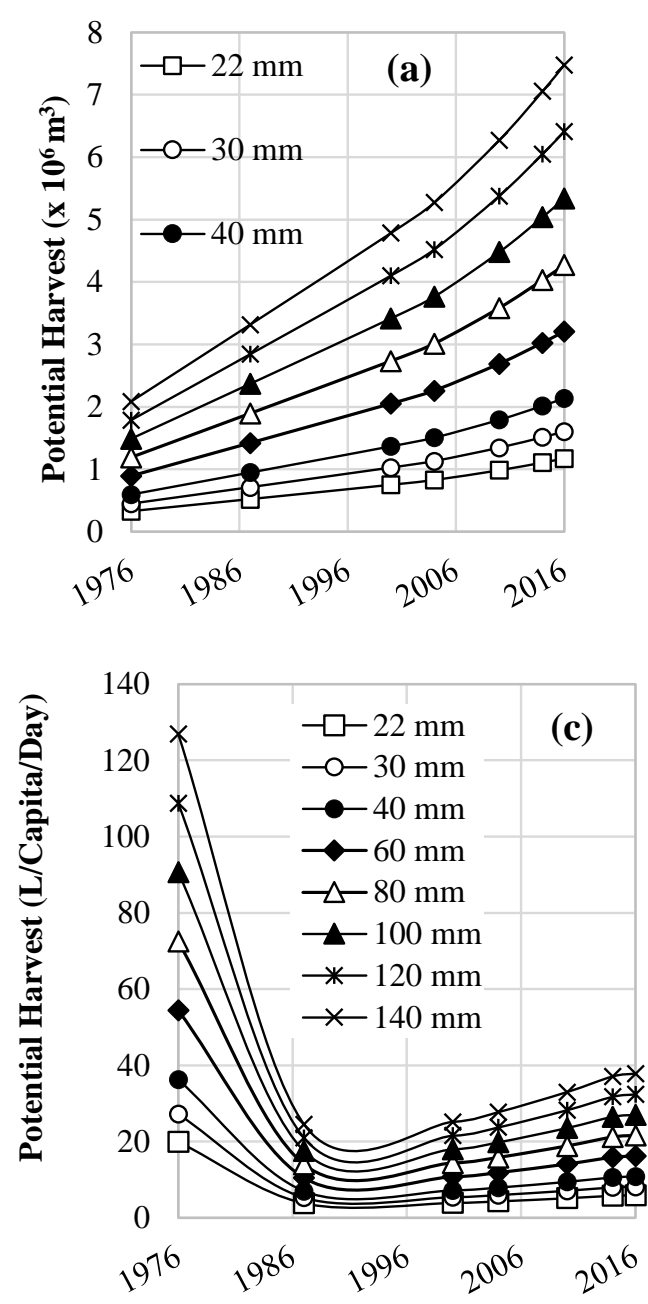
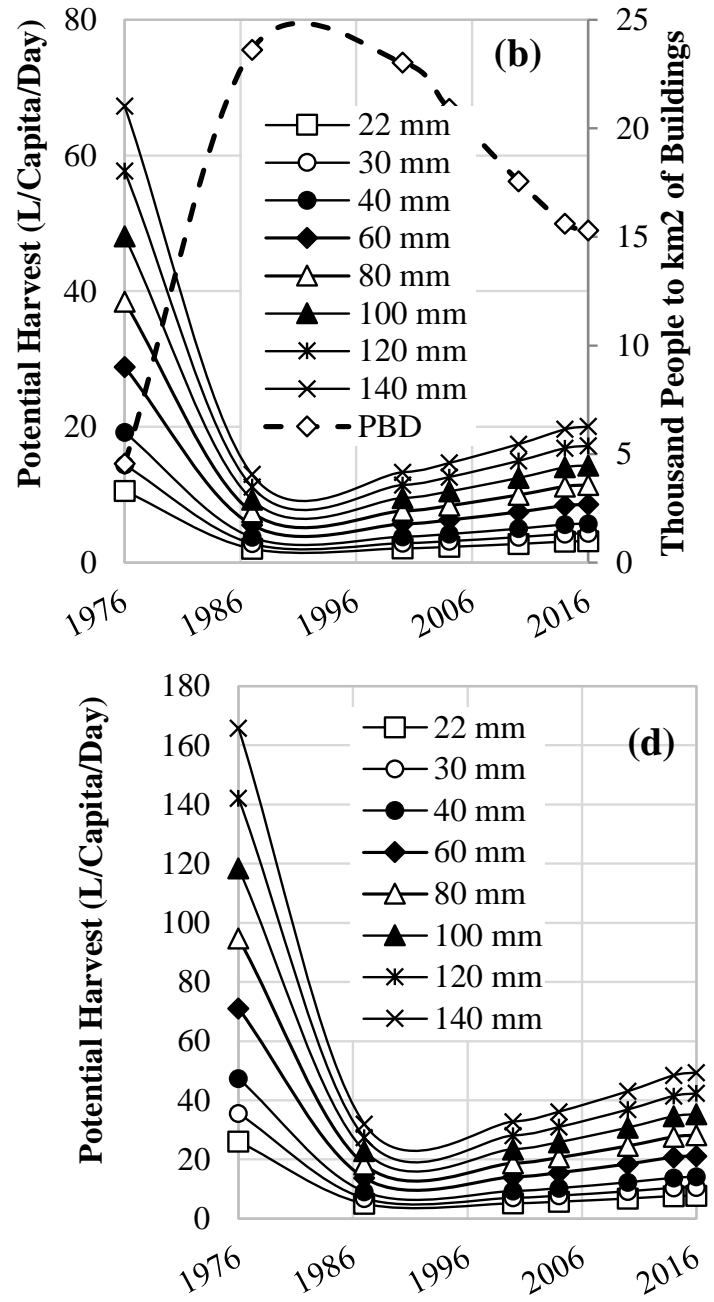

Figure 13. Assessment of rainwater harvesting potential in Sharjah due to urbanization during 1976-2016: (a) rainwater harvesting potential (in $\mathrm{m}^{3}$ ) from rooftops of buildings with different amounts of rainfall; (b) per capita potential rainwater harvesting in the city averaged over the whole year; (c) per capita potential rainwater harvesting in the city averaged over six months (rainy season); and (d) per capita potential rainwater harvesting in the city averaged over four months (winter season).

The available data suggests that the population to building area ratio (i.e., population to building density, PBD) increased between 1976 and 1987, from about 5000 people $/ \mathrm{km}^{2}$ to about 24,000 people $/ \mathrm{km}^{2}$. During that period, the main parts of the city became nearly saturated with multi-story buildings. On the other hand, the inland expansion of the city starting in the 1990s involved the building of detached family dwellings, which helped to reduce the PBD after 1987 to about 15,000 people $/ \mathrm{km}^{2}$ in 2016. The per capita water harvest reflected the PBD, as did precipitation. As can be seen in 
Figure $13 \mathrm{~b}-\mathrm{d}$, for the average annual rainfall of approximately $100 \mathrm{~mm} /$ year in the city, the annual water harvest reached an average of $15 \mathrm{~L} /$ capita per day over 365 days, $30 \mathrm{~L} /$ capita per day over 180 days of the rainy season, and about $40 \mathrm{~L} /$ capita per day over 120 days of the rainy season. The per capita potential rain harvest numbers are significant and constitute approximately $10 \%$ to $30 \%$ of the water consumption of residents (approximately $200 \mathrm{~L} /$ capita/day) in Sharjah city.

\section{Summary and Conclusions}

In this study, land cover change (urbanization) in Sharjah city over the period of 1976-2016 was investigated. A pattern of regular expansion off the coastal areas, toward the Southeastern parts of the city, was observed over the 40-year period. This interesting development was noticed after 2000 when the most Southeastern part of the city started to host residential and commercial real estate as a result of establishing the University of Sharjah. The downtown area was well-developed, despite space being very limited for horizontal development. Nevertheless, the area continued its development trend that resulted in a high concentration of buildings and roads in the downtown area (high rise building-land use). Overall, the amount of built areas in Sharjah city have increased by four-fold over 1976-2016, which reflects the rapid urbanization trend in the city.

Then, the effects of urbanization on runoff characteristics and rainwater harvesting potential were examined. Also, a flood map was generated for Sharjah city, considering excess rain, elevation and slope factors. The flood maps were partially verified through field observations of flood locations following rainfall events. The results were integrated in a GIS environment to investigate urbanization effects on the flood extent for different land use zones. The minimum precipitation required to generate runoff decreased by around 30\% (from about $15 \mathrm{~mm}$ in 1976 to about $10 \mathrm{~mm}$ in 2016) in built areas. The generated flood maps showed that industrial and residential land use zones are the most flood sensitive regions in Sharjah city. However, due to rapid urbanization in the residential land use zone, the most significant increase in flood extent was examined in the residential land use zone. In parallel to rapid urbanization in Sharjah city, the rainwater harvesting potential significantly increased.

A proper urban drainage system has not been constructed in the region due to rare rainfall events. However, this study showed that urbanization in Sharjah has significantly affected the runoff characteristics and flood potential of the region. Since further urbanization is unavoidable in the city (and also climate change has adverse effects on flooding potential), it is important to develop flood management policies and actions for the city.

Since urban drainage systems require a massive investment, some alternative rainwater management strategies should be considered in the region. For instance, vegetated swales could be considered as an alternative to an urban drainage system or they could serve as part of an urban drainage system. Swales are used to promote infiltration and reduce the flow velocity of rainwater runoff [37].

As explained earlier, increased urbanization has increased the rainwater harvesting capacity from the rooftops of buildings. Rainwater harvesting can be achieved using rainwater tanks and filtration/infiltration trenches. In addition to rainwater harvesting, paved areas could be minimized or replaced with porous paving, and also a variety of landscape measures and practices could be applied to reduce the volume of rainwater runoff to decrease the effects of floods. These practices support the sustainability goal of the Sharjah city and may provide feasible solutions in the long-term.

In addition to the abovementioned alternatives, urban drainage shafts could be considered for the locations in Sharjah city that are subject to severe local flooding (i.e., residential and industrial land use zones). It is important to conduct a detailed economic feasibility study for urban drainage solutions (e.g., conventional urban drainage systems, urban drainage shafts, and sustainable urban drainage alternatives) in Sharjah city to select the best alternative to stop/reduce local flooding. However, an economic feasibility evaluation of those solutions is beyond the scope of this paper.

It is worth mentioning an important drawback caused by the lack of observed runoff data in this study. It is general practice in the literature to use hydrological models to investigate land cover 
change (urbanization) effects on runoff characteristics (floods), as done by Chu et al. [7] and Nigussie and Altunkaynak [10]. Since runoff data was not available for the study area, the SCS method was used to generate excess rain (surface runoff) data based on different land use zones, and this excess rain data was used for the investigation of the urbanization influence on the runoff characteristics of the city and for the generation of flood maps. It is recommended that future studies use runoff data in suitable hydrological models to investigate the relationship between urbanization and floods.

Author Contributions: A.S., A.G.Y., R.A. and M.A.I. performed hydrological analysis, R.A., A.S. and A.G.Y. performed urbanization analysis through image processing and GIS techniques. M.S. and T.M. conducted rainfall analysis for potential flood mapping. A.S., R.A. and A.G.Y. conceptualized the paper and prepared the manuscript.

Conflicts of Interest: The authors declare no conflict of interest.

\section{References}

1. Du, S.; Shi, P.; Van Rompaey, A.; Wen, J. Quantifying the impact of impervious surface location on flood peak discharge in urban areas. Nat. Hazards 2015, 76, 1457-1471. [CrossRef]

2. Ogden, F.L.; Raj Pradhan, N.; Downer, C.W.; Zahner, J.A. Relative importance of impervious area, drainage density, width function, and subsurface storm drainage on flood runoff from an urbanized catchment. Water Resour. Res. 2011, 47, 1-12. [CrossRef]

3. Du, J.; Qian, L.; Rui, H.; Zuo, T.; Zheng, D.; Xu, Y.; Xu, C.Y. Assessing the effects of urbanization on annual runoff and flood events using an integrated hydrological modeling system for Qinhuai River basin, China. J. Hydrol. 2012, 464-465, 127-139. [CrossRef]

4. Suriya, S.; Mudgal, B.V. Impact of urbanization on flooding: The Thirusoolam sub watershed-A case study. J. Hydrol. 2012, 412-413, 210-219. [CrossRef]

5. Choi, J.Y.; Engel, B.A.; Muthukrishnan, S.; Harbor, J. GIS based long term hydrologic impact evaluation for watershed urbanization. JAWRA J. Am. Water Resour. Assoc. 2003, 39, 623-635. [CrossRef]

6. Franczyk, J.; Chang, H. The effects of climate change and urbanization on the runoff of the Rock Creek basin in the Portland metropolitan area, Oregon. USA. Hydrol. Process. 2009, 23, 805-815. [CrossRef]

7. Chu, H.J.; Lin, Y.P.; Huang, C.W.; Hsu, C.Y.; Chen, H.Y. Modelling the hydrologic effects of dynamic land-use change using a distributed hydrologic model and a spatial land-use allocation model. Hydrol. Process. 2010, 24, 2538-2554. [CrossRef]

8. Sharif, H.O.; Al-Juaidi, F.H.; Al-Othman, A.; Al-Dousary, I.; Fadda, E.; Jamal-Uddeen, S.; Elhassan, A. Flood hazards in an urbanizing watershed in Riyadh, Saudi Arabia. Geomat. Nat. Hazards Risk 2016, 7, 702-720. [CrossRef]

9. Zope, P.E.; Eldho, T.I.; Jothiprakash, V. Impacts of urbanization on flooding of a coastal urban catchment: A case study of Mumbai City, India. Nat. Hazards 2015, 75, 887-908. [CrossRef]

10. Nigussie, T.A.; Altunkaynak, A. Assessing the Hydrological Response of Ayamama Watershed from Urbanization Predicted under Various Landuse Policy Scenarios. Water Resour. Manag. 2016, 30, 3427-3441. [CrossRef]

11. Al-Rawas, G.A.; Valeo, C.; Khan, U.T.; Al-Hafeedh, O.H. Effects of urban form on wadi flow frequency analysis in the Wadi Aday watershed in Muscat, Oman. Urban. Water J. 2015, 12, 263-274. [CrossRef]

12. Huang, Q.; Wang, J.; Li, M.; Fei, M.; Dong, J. Modeling the influence of urbanization on urban pluvial flooding: A scenario-based case study in Shanghai, China. Nat. Hazards 2017, 87, 1035-1055. [CrossRef]

13. Schilling, K.E.; Chan, K.-S.; Liu, H.; Zhang, Y.-K. Quantifying the effect of land use land cover change on increasing discharge in the Upper Mississippi River. J. Hydrol. 2010, 387, 343-345. [CrossRef]

14. Ali, M.; Khan, S.J.; Aslam, I.; Khan, Z. Simulation of the impacts of land-use change on surface runoff of Lai Nullah Basin in Islamabad, Pakistan. Landsc. Urban Plan. 2011, 102, 271-279. [CrossRef]

15. Turnbull, L.; Wainwright, J.; Brazier, R.E. Changes in hydrology and erosion over a transition from grassland to shrubland. Hydrol. Process. 2010, 24, 393-414. [CrossRef]

16. Alexakis, D.D.; Grillakis, M.G.; Koutroulis, A.G.; Agapiou, A.; Themistocleous, K.; Tsanis, I.K.; Michaelides, S.; Pashiardis, S.; Demetriou, C.; Aristeidou, K.; et al. GIS and remote sensing techniques for the assessment of land use change impact on flood hydrology: The case study of Yialias basin in Cyprus. Nat. Hazards Earth Syst. Sci. 2014, 14, 413-426. [CrossRef] 
17. Chen, J.; Theller, L.; Gitau, M.W.; Engel, B.A.; Harbor, J.M. Urbanization impacts on surface runoff of the contiguous United States. J. Environ. Manag. 2017, 187, 470-481. [CrossRef] [PubMed]

18. Liu, C.; Li, Y.; Li, J. Geographic information system-based assessment of mitigating flash-flood disaster from green roof systems. Comput. Environ. Urban Syst. 2017, 64, 321-331. [CrossRef]

19. Shanableh, A.; Al-Ruzouq, R. Integration of multi-temporal satellite imagery in modeling urban expansion effects on runoff in the city of Sharjah, United Arab Emirates. In Proceedings of the Hydrology and Water Resources Symposium 2014, Berth, Australia, 24-27 February 2014; pp. 223-230.

20. Shanableh, A.; Al-Ruzouq, R.; Siddique, M.; Merabtene, T.; Yilmaz, A.; Imteaz, M. Impact of urban expansion on potential flooding, storage and water harvesting in the city of Sharjah, United Arab Emirates. In Proceedings of the Advances in Sustainable Construction Materials \& Civil Engineering Systems (ASCMCES-17) Conference, Sharjah, UAE, 18-20 April 2017.

21. Al-Ruzouq, R.I. Data fusion of multi-source imagery based on linear features registration. Int. J. Remote Sens. 2010, 31, 5011-5021. [CrossRef]

22. Al-Ruzouq, R.; Hamad, K.; Shanableh, A.; Khalil, M. Infrastructure growth assessment of urban areas based on multi-temporal satellite images and linear features. Ann. GIS 2017, 1-19. [CrossRef]

23. Al-Ruzouq, R.I.; Habib, A.F. Linear features for automatic registration and reliable change detection of multi-source imagery. J. Spat. Sci. 2012, 57, 51-64. [CrossRef]

24. Weng, Q. Modeling urban growth effects on surface runoff with the integration of remote sensing and GIS. Environ. Manag. 2001, 28, 737-748. [CrossRef]

25. Mockus, V.; Hjelmfelt, A.T. Chapter 10: Estimation of Direct Runoff from Storm Rainfall. In Part 630 Hydrology National Engineering Handbook; United States Department of Agriculture: Washington, DC, USA, 2004; p. 79.

26. Merabtene, T.; Siddique, M.; Shanableh, A. Assessment of Seasonal and Annual Rainfall Trends and Variability in Sharjah City, UAE. Adv. Meteorol. 2016, 2016. [CrossRef]

27. Sherif, M.; Almulla, M.; Shetty, A.; Chowdhury, R.K. Analysis of rainfall, PMP and drought in the United Arab Emirates. Int. J. Climatol. 2014, 34, 1318-1328. [CrossRef]

28. Saaty, T.L. The Analytic Hierarchy Process.: Planning, Priority Setting, Resource Allocation; McGraw-Hill: New York, NY, USA, 1980.

29. Ouma, Y.O.; Tateishi, R. Urban flood vulnerability and risk mapping using integrated multi-parametric AHP and GIS: Methodological overview and case study assessment. Water 2014, 6, 1515-1545. [CrossRef]

30. Forman, E.; Gass, S. The Analytic Hierarchy Process-An Exposition. Oper. Res. 2001, 49, 469-486. [CrossRef]

31. Lyu, H.M.; Sun, W.J.; Shen, S.L.; Arulrajah, A. Flood risk assessment in metro systems of mega-cities using a GIS-based modeling approach. Sci. Total Environ. 2018, 626, 1012-1025. [CrossRef]

32. Chen, Y.R.; Yeh, C.H.; Yu, B. Integrated application of the analytic hierarchy process and the geographic information system for flood risk assessment and flood plain management in Taiwan. Nat. Hazards 2011, 59, 1261-1276. [CrossRef]

33. Sutadian, A.D.; Muttil, N.; Yilmaz, A.G.; Perera, B.J.C. Using the Analytic Hierarchy Process to identify parameter weights for developing a water quality index. Ecol. Indic. 2017, 75, 220-233. [CrossRef]

34. Al-Ruzouq, R.I.; Al-Zoubi, A.; Akawi, E.E.; Abueladas, A.A.; Niemi, T.M. Multiple source imagery and linear features for detection of urban expansion in Aqaba City, Jordan. Int. J. Remote Sens. 2012, 33, 2563-2581. [CrossRef]

35. Hsieh, J.; Liao, H.; Fan, K.; Ko, M.; Hung, Y. Image Registration Using a New Edge-Based Approach. Comput. Vis. Image Underst. 1997, 67, 112-130. [CrossRef]

36. Cavallaro, A.; Touradj, E. Change Detection Based on Color Edges. In Proceedings of the IEEE International Symposium on Circuits and Systems (ISCAS-2001), Sydney, NSW, Australia, 6-9 May 2001.

37. Pavan Kumar, K.; Barik, D.K.; Manideep, C. A Comparative Study of Storm Water Drainage Methods for Urban Storm Water Management. Indian J. Sci. Technol. 2015, 8. [CrossRef]

(C) 2018 by the authors. Licensee MDPI, Basel, Switzerland. This article is an open access article distributed under the terms and conditions of the Creative Commons Attribution (CC BY) license (http://creativecommons.org/licenses/by/4.0/). 